\title{
Takayasu arteritis in an adolescent with Crohn's disease
}

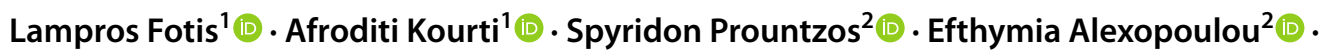 \\ Vasiliki Papaevangelou ${ }^{1}(1) \cdot$ Smaragdi Fessatou ${ }^{1}(1)$
}

Received: 15 March 2021 / Accepted: 13 April 2021 / Published online: 27 April 2021

(C) The Author(s), under exclusive licence to Springer-Verlag GmbH Germany, part of Springer Nature 2021

\begin{abstract}
Crohn's disease (CD) and Takayasu arteritis (TA) are two distinct clinical entities. The likelihood of both diseases coexisting is low, and although CD co-occurs with all types of vasculitis, TA is the most common subtype. Herein, the case of a 15-year-old female, diagnosed with TA following an initial diagnosis of $\mathrm{CD}$, is reported. A review of the literature, including a systemic review of the case reports and case series of children and adolescents up to the age of 21, with both CD and TA, follows the case description. In total, 28 cases of TA and CD were retrieved. The median age of patients was 14.8 years, they were mostly females $(72 \%)$ and the median time between the two diagnoses was 3.7 years. In the majority of cases, CD was diagnosed first and TA followed. Computed tomography angiography and magnetic resonance angiography were the preferred imaging modalities to assist diagnosis.
\end{abstract}

Keywords Adolescence $\cdot$ Child $\cdot$ Crohn's disease $\cdot$ pediatric $\cdot$ Takayasu arteritis $\cdot$ TNF blockers $\cdot$ Vasculitis

\section{Introduction}

Crohn's disease (CD) is a chronic granulomatous inflammatory disorder that can involve any part of the gastrointestinal (GI) tract. It is characterized by transmural inflammation, resulting in significant complications such as abscesses, fistulas, and strictures. Clinical features include abdominal

Lampros Fotis

lafotis@med.uoa.gr

Afroditi Kourti

afroditi_kourti@yahoo.gr

Spyridon Prountzos

spyttt@gmail.com

Efthymia Alexopoulou

ealex64@hotmail.com

Vasiliki Papaevangelou

vpapaev@gmail.com

Smaragdi Fessatou

sfessatou@yahoo.gr

1 Department of Pediatrics, National and Kapodistrian University of Athens, "ATTIKON" General Hospital, 1 Rimini Str, Chaidari, 12462 Athens, Greece

2 Department of Radiology, National and Kapodistrian University of Athens, "ATTIKON" General Hospital, 1 Rimini Str, Chaidari, 12462 Athens, Greece pain, diarrhea, fever, and weight loss, often associated with extra-intestinal complications, involving various organs such as the skin, eyes, joints, and cardiovascular system [1].

Takayasu's arteritis (TA) on the other hand is a rare, chronic, idiopathic granulomatous, relapsing large vessel vasculitis affecting the aorta and its major branches. It leads to wall thickening, fibrosis, stenosis, occlusion and aneurysm formation. Clinical features range from asymptomatic disease often incidentally discovered as absent limb pulses to nonspecific features of fever, malaise, weight loss, arthralgia, myalgia, and anemia to organ-specific ischaemic phenomena. The absence of peripheral pulses has given it the name "pulseless disease" [2]. Several case reports have noted TA and CD in the same patient, though such coexistence has been theoretically estimated to occur in only 1 in 10 million individuals [3]. Although CTA and MRA have been the preferred imaging diagnostic modalities for the past several years, 18-fluorodeoxy-glucose positron emission tomography/computed tomography $18 \mathrm{~F}-\mathrm{FDG}$ PET/CT has been increasingly recognized as an important diagnostic tool [4]. It is sensitive in showing increased uptake in the aorta and its large proximal branches that are involved in large vessel vasculitis (Giant cell and Takayasu arteritis) and thus it has been strongly recommended as a tool for the early diagnosis of vasculitis by the European League Against Rheumatism (EULAR) [5]. 
Herein, we describe a 15-year-old female initially diagnosed with $\mathrm{CD}$, later developing features of TA while receiving treatment with infliximab. As the $\mathrm{CD}$ activity was well controlled with infliximab, the occurrence of TA was an unexpected event in this patient. A systemic review of the case reports and case series of TA associated with CD in young patients under 21 years old follows the case description. Written informed consent was provided by the patient and her family for the case description.

\section{Case report}

A 14-year-old female was diagnosed with $C D$ when she presented with a history of fever for a week, accompanied by mouth aphthous ulceration and abdominal pain. Her laboratory testing when admitted to our institution showed white blood count (WBC) $15,400 / \mu \mathrm{L}$ (reference range 4000-11,000), hemoglobin (Hb) $8.1 \mathrm{~g} / \mathrm{dl}(12-15)$, platelets (PLTs) $692,000 / \mu \mathrm{L}(150,000-400,000)$, C-reactive protein (CRP) $78 \mathrm{mg} / \mathrm{L}(<6)$, erythrocyte sedimentation rate (ESR) $35 \mathrm{~mm} / \mathrm{h}(<20)$ and elevated fecal calprotectin $($ FCAL) $836 \mu \mathrm{g} / \mathrm{g}(<50 \mu \mathrm{g} / \mathrm{g})$. Upper and lower GI endoscopy showed regional inflammation of the stomach and the colon (Fig. 1). Histology revealed granulomatous colitis, inflamed mucosa of the colon with inflammatory epithelial damage, and focal mild crypt distortion confirming the diagnosis of CD. Magnetic resonance enterography (MRE) revealed active disease in terminal ileum and cecum.

Her past medical history was remarkable for a series of hospitalizations in another institution between the age of 7.5 and 11 years. The main symptom was fever of unknown origin, lasting up to 30 days. Accompanying symptoms were arthralgias, but no arthritis was ever documented. During those episodes, she had elevated ESR and CRP, but her workup including rheumatology, infectious disease studies and hematology/oncology consultations was not diagnostic. At the age of 11, during her last hospitalization, she underwent upper and lower GI endoscopy. This revealed mild but nonspecific inflammation to substantiate the diagnosis of inflammatory bowel disease (IBD) and no treatment was initiated.

Her family history was remarkable for her maternal grandmother having Hashimoto thyroiditis and psoriasis and her maternal uncle and aunt having a diagnosis of systemic lupus erythematosus.

Following the diagnosis of $\mathrm{CD}$, she was started on mesalazine $(50 \mathrm{mg} / \mathrm{kg})$ and azathioprine $(2.5 \mathrm{mg} / \mathrm{kg})$, that was discontinued a month later due to persistently elevated liver enzymes. Therefore, infliximab treatment was initiated at a dose of $5 \mathrm{mg} / \mathrm{kg}$ every 8 weeks.

The disease was well controlled for 1 year, but at age 15 , she was admitted with 5 days of fever up to $39^{\circ} \mathrm{C}$, malaise during fever episodes, abdominal and low back pain. Her physical examination was remarkable for scalp psoriasis. Her laboratory testing was as follows: WBC $15,500 / \mu \mathrm{L}$ (Neutrophils 79\%, Lymphocytes 14\%, Monocytes 9\%), Hb 9.6 g/ $\mathrm{dL}$, PLTs 716,000 K/ $\mu \mathrm{L}$, CRP $142 \mathrm{mg} / \mathrm{L}$, ESR $140 \mathrm{~mm} / \mathrm{hr}$, glucose $85 \mathrm{mg} / \mathrm{dL}$ (74-106), urea $19.3 \mathrm{mg} / \mathrm{dL}$ (16.6-48.5), creatinine $0.6 \mathrm{mg} / \mathrm{dL}(0.5-0.9)$, Aspartate aminotransferase (AST) $26 \mathrm{U} / \mathrm{L}(<32)$, Alanine aminotransferase (ALT) $33 \mathrm{U} / \mathrm{L}$ (<33), Gamma-glutamyl transferase (GGT) $32 \mathrm{U} / \mathrm{L}$ (5.0-36.0), total protein $9.0 \mathrm{~g} / \mathrm{dL}$ (6.6-8.7), albu$\min 4.1 \mathrm{~g} / \mathrm{dL}$ (3.5-5.2). Infectious disease workup including blood-urine-stool cultures, film-array for respiratory viruses and PCR for the detection of SARS-CoV-2 in nasopharyngeal swab, Quantiferon gold and serology tests and blood PCR for EBV and CMV were all negative. Total $\mathrm{IgG}$ was $18.6 \mathrm{~g} / \mathrm{L}$ (7.0-16.0), IgM $1.57 \mathrm{~g} / \mathrm{dL}(0.4-2.3), \operatorname{IgA} 5.52 \mathrm{~g} / \mathrm{dL}$ (0.7-4.0), IgE $357 \mathrm{IU} / \mathrm{m}$ (<100), IgG1 15.2 g/L (3.7-12.8), IgG2 $3.56 \mathrm{~g} / \mathrm{L}$ (1.06-6.1), IgG3 $1.040 \mathrm{~g} / \mathrm{L}$ (0.18-1.63), IgG4 $2.550 \mathrm{~g} / \mathrm{L}(0.04-2.3)$, serum angiotensin-converting enzyme (SACE) 34.7 U/L (8.0-52.0). ANA, RF and ANCA were negative, C3 $161 \mathrm{mg} / \mathrm{dL}$ (90-180), C4 $90 \mathrm{mg} / \mathrm{dL}$ (10-40) and FCAL was $271 \mu \mathrm{g} / \mathrm{g}$. Urinalysis did not reveal proteinuria or hematuria. Electro- and echocardiogram were within normal limits. Computed tomography (CT) of the abdomen showed thickened wall of the terminal ileum but bilateral pleural effusion incidentally was revealed. Chest CT confirmed the bilateral pleural effusion but had no other
Fig. 1 Endoscopic images with aphthous and longitudinal ulcers (arrows), typical of Crohn's disease

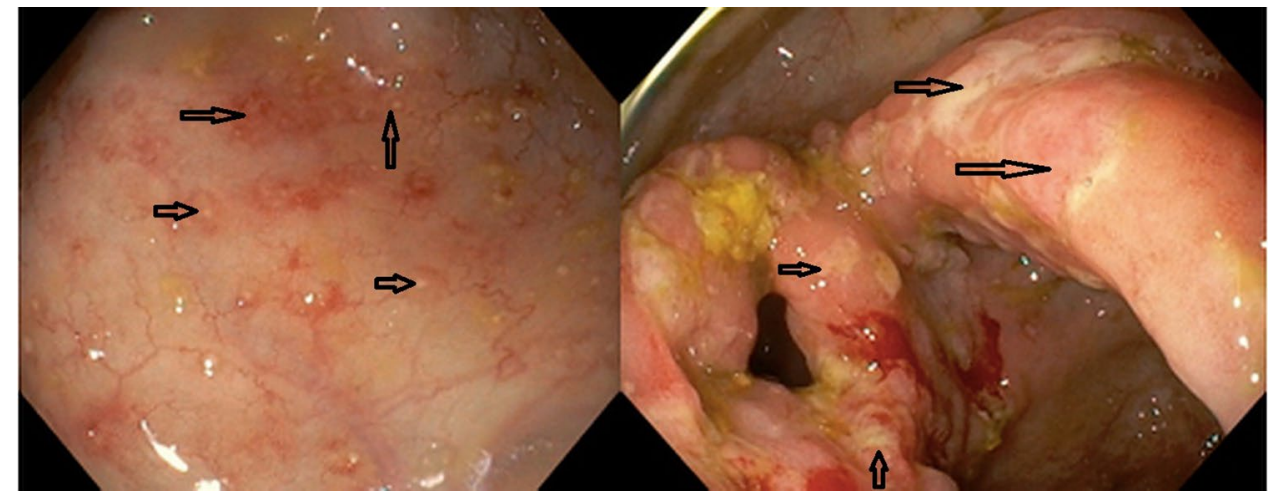


abnormal findings. Whole-genome sequencing revealed a mutation in INAVA gene (C1orf106). This mutation has been associated with increased risk of developing IBD and has no other correlations with any other autoimmune disorders [6]. Infliximab was discontinued, as it failed to control the disease, while it caused psoriatic rash eruption, and methotrexate $20 \mathrm{mg}$ /week with prednisolone $40 \mathrm{mg}$ /day was started. Her symptoms improved and she was discharged.

Two months later, and 1 week after prednisolone was discontinued, her fever relapsed. At that time, Chest CT angiogram demonstrated left subclavian artery and bilateral main and lobar pulmonary arteries wall thickening, but no luminal narrowing or occlusion (Fig. 2). At that time, the differential diagnosis included IBD-related arteritis/ periarteritis, IgG4-related disease, and Takayasu arteritis. A Positron Emission Tomography-Computed Tomography (PET-CT) was ordered, with the aim of detecting other areas of arterial inflammation and showed increased uptake value of the aortic arch wall, the left subclavian and bilateral pulmonary arteries. Following that, she received treatment with
IV methylprednisolone 1 gram for 3 consecutive days. The fever subsided, the laboratory parameters improved, and she was discharged on per os prednisolone $40 \mathrm{mg} /$ day on a slow tapering, methotrexate $20 \mathrm{mg}$ /week and adalimumab $40 \mathrm{mg} /$ q2weeks. Adalimumab was selected over restarting Infliximab as although it could be infused in higher doses and shorter intervals, it initially failed to control the disease and it was considered as the trigger for psoriatic rash eruption. A follow-up magnetic resonance angiogram (MRA) of the chest, 3 months later, and while ESR and CRP were within normal limits, showed arterial wall thickening and late gadolinium wall enhancement, a finding consistent with persistent disease activity of TA (Fig. 3). Currently, the patient is doing well on prednisolone $15 \mathrm{mg} /$ day, methotrexate $20 \mathrm{mg} /$ week and adalimumab $40 \mathrm{mg} /$ every 2 weeks.

\section{Search strategy}

The search strategy of the current review was based upon the recommendations published in Rheumatology International
Fig. 2 CTA of the thoracic aorta and pulmonary arteries. a Reveals wall thickening of the left main pulmonary artery (arrows). b Wall thickening at the origin of the left subclavian artery (arrows)
Fig. 3 MRA of the thoracic great vessels (sagittal viewdelayed phase). a At the level of aortic arch reveals increased contrast uptake with wall thickening of the origin of the left subclavian artery plus increased uptake of the aortic arch. (arrowhead). b At the lever of the right hilum reveals increased contrast uptake with wall thickening of right pulmonary lobar arteries (arrows)
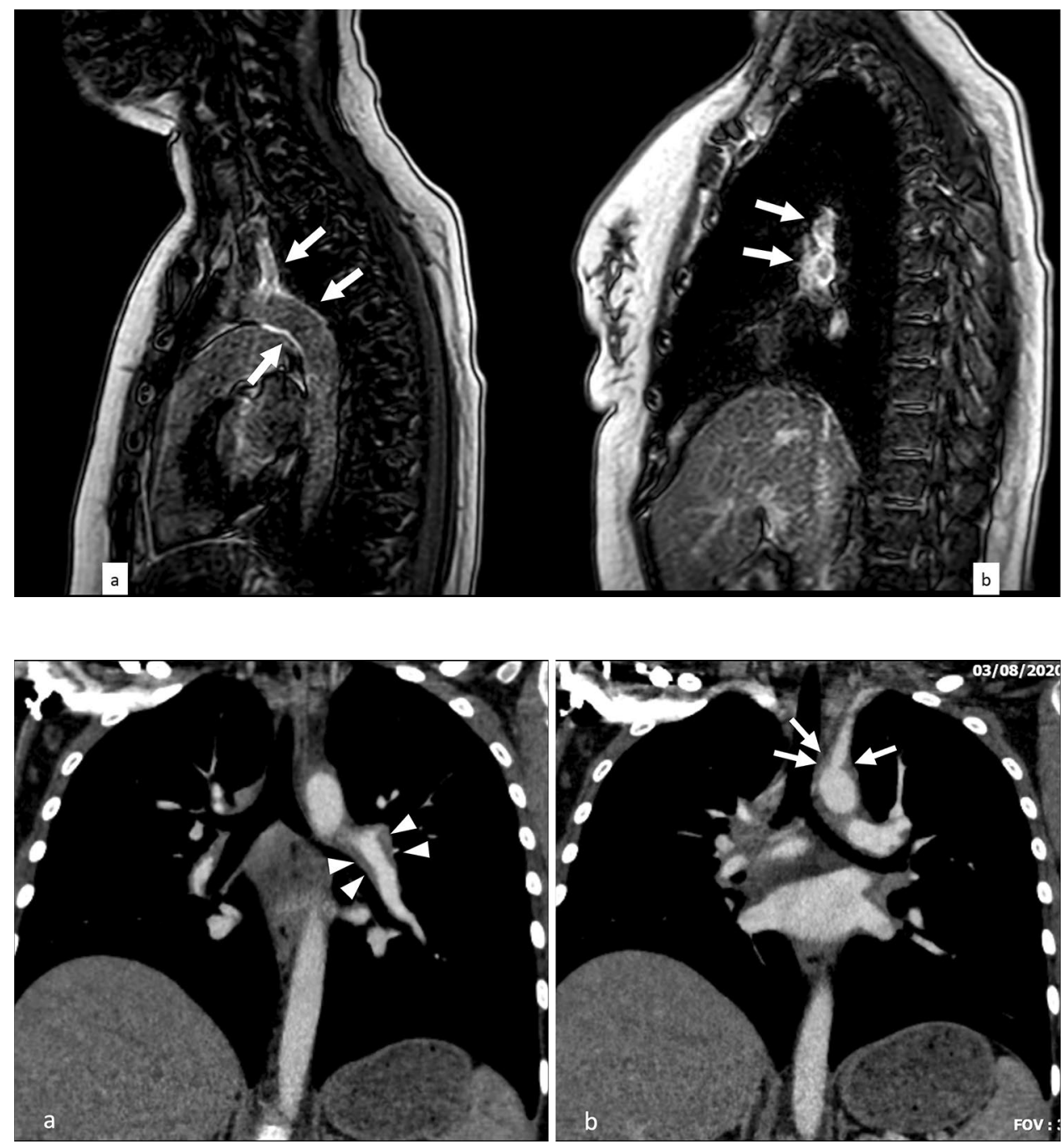
[7]. We searched PubMed, PubMed Central, Scopus, Web of Science, and ScienceDirect from 1976 up to 31 December 2020 combining the keywords Crohn's disease; Takayasu arteritis; and inflammatory bowel disease. We further searched the reference lists of identified articles for additional papers. We included case reports or case series of patients age $<21$ years. We restricted results on English language published papers.

\section{Discussion}

In the case presented, the latent time for $\mathrm{CD}$ diagnosis was 3 years, following the initial upper and lower GI endoscopy that was not diagnostic at age 11. This is often the case in $\mathrm{CD}$, as the latent time of diagnosis ranges from 2 months to 2 years [8]. Although, before establishing the diagnosis of $\mathrm{CD}$, no vessel imaging with CTA, MRA or PET-CT was obtained, most likely previous symptoms were not associated to vasculitis, as it is uncommon for this type of disease to manifest with recurrent and self-limited episodes of fever. In addition, after establishing the diagnosis of TA, there was no evidence of luminal stenosis or occlusion, suggestive of previous disease activity. In addition, the possibility of granulomatous vasculitis associated to Crohn's disease itself, cannot be excluded, as it may affect the aorta but most commonly the intestinal vessel wall $[9,10]$.

Although, no systolic blood pressure discrepancy between the limbs, no limb pulse deficit or claudication, no murmurs or palpable thrills over large arteries or no hypertension was documented at diagnosis, the patient fulfilled the EULAR/ PRINTO/PRES criteria for childhood TA as there was evidence of arterial wall thickening (aorta, left subclavian artery, left pulmonary artery) plus significant elevated ESR and CRP [11,12].

Both Takayasu arteritis and Crohn's disease are rare. The incidence of TA in adults has been reported to be $1 / 1,000,000 /$ year in Europe with a female:male ratio of 1.2:1 [13]. No data for the disease prevalence is available. The incidence of CD is approximately $2 / 100,000 /$ year and the prevalence of $\mathrm{CD}$ in Europe has been reported to vary between 10 and 150 per 100,000 inhabitants [14]. The likelihood of both diseases coexisting in the same patient by chance alone has been estimated to be 1 in 10 million individuals [3]. However, it has been observed that IBD co-occurs with all types of vasculitis more frequently than it would be expected, with TA being the most common vasculitis subtype [15]. It seems that this occurs in younger patients compared to those with TA alone and is far more common in female patients. In the majority of cases, IBD occurs first and TA follows, although the opposite has been reported or even both diagnoses have been established simultaneously [15]. Prior to this case and since 1976, only 28 cases of IBD-TA coexistence in adolescents have been reported [3, 15-38] (Table 1). However, in adult studies, the concurrence rate in patients with IBD reaches as high as 9.2\% [39-41].

The pathogenesis of both TA and IBD remains unclear. However, a common pathogenic mechanism between the two diseases is conceivable. Granulomatous inflammation due to cell-mediated injury is the common pathophysiological mechanism seen in both conditions, suggesting that simultaneous occurrence is more than just a coincidence $[42,43]$. The underlying inflammatory process in both diseases appears to be influenced by cytokines such as tumor necrosis factor $\alpha(\mathrm{TNF}-\alpha)$ and interleukins including IL-6, IL-8, IL-12 and IL-18 [42, 43]. Various HLA haplotypes B52*01, DRB-1*15:02-DQA- $1 * 01: 03$ DQB-1*06:01-DPB-1*09:01 have been associated with the concurrence of TA and IBD in Japanese patients [40, 41]. Infectious agents such as Mycobacterium tuberculosis have been implicated as common etiologies, but to date no definite etiological association has been identified [44].

TA is a panarteritis associated with edema, mononuclear cell infiltration (CD4 and CD8 lymphocytes, plasma cells, and macrophages) in the outer thirds of the media and adventitia, giant cell granulomatous reaction and laminar necrosis [45]. CD is an inflammatory bowel disease characterized by mucosal ulceration, crypt architectural changes, colonic Paneth cell metaplasia, transmural inflammatory infiltrate by neutrophils, submucosal fibrosis and noncaseating granulomas [46]. Interestingly, focal granulomatous vasculitis has been reported in the diseased portions of the bowel in patients with CD [10]. The development of granulomas and granulomatous vasculitis seen in both CD and TA may suggest a common pathophysiologic mechanism.

In Table 1, including the case presented, 29 cases of CD and TA co-occurrence in adolescents reported in literature are listed [3, 15-38]. Most of them were female (21/29) with a median age of 14.8 years (IQR, 13-17 years old). It seems that TA either presents simultaneously or following the diagnosis of $\mathrm{CD}$ and is unlikely to precede $\mathrm{CD}$ manifestations. The median latent time between the two diagnosis is 4 years (IQR, 1-5 years). From the cases listed in Table 1, almost $1 / 3$ of the patients presented with gastrointestinal symptoms, including abdominal pain, nausea, diarrhea, 8 patients presented with fever, another 4 had hypertension and interestingly chest/neck/back pain was described by 9 patients as the presenting symptoms of TA. The variety of symptoms at the presentation of TA indicates the difficulty in the differential diagnosis. To establish the diagnosis, an imaging technique was always required. In the vast majority of cases during the last 15 years CTA and/or MRA were the preferred techniques. In the past, aortogram was the preferred diagnostic technique $[3,15,21-35]$. 


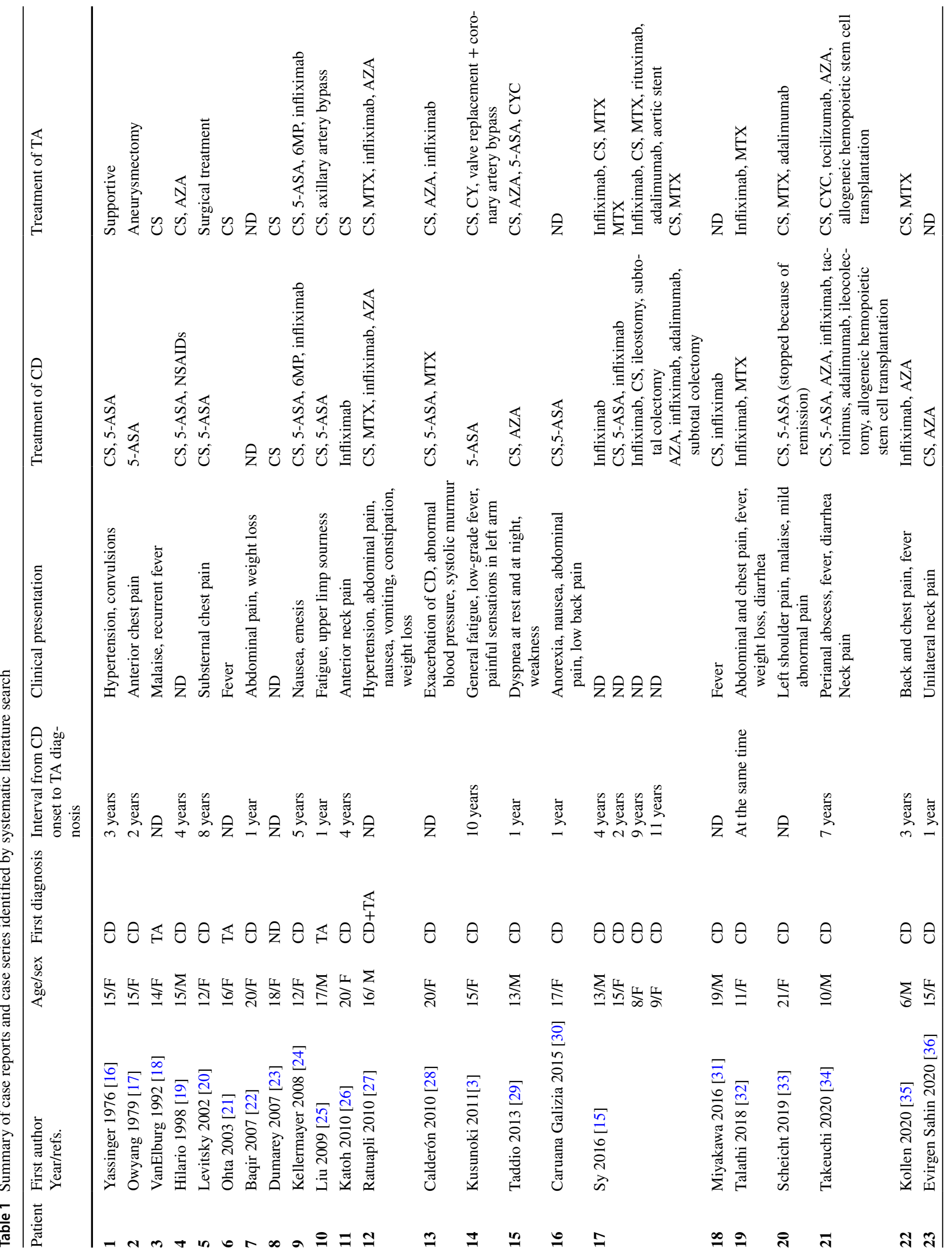


In terms of diagnostics, there is no single modality that provides all the information required. Suggested imaging techniques are CTA, MRA, PET-CT, ultrasound and digital subtraction angiography and have distinct and complementary roles [47, 48]. MRA and CTA are of equal value for imaging of the great vessel's lumen [49]. However, MRA has the advantage of minimizing exposure to radiation, while it also provides information on arterial wall thickness, edema and late gadolinium enhancement [49]. PET-CT is useful for the detection of active large vessel vasculitis. It provides information about disease activity that is complimentary to other imaging modalities and the clinical assessment, but currently it is not used for serial monitoring of vascular inflammation in routine clinical practice. The radiation dose is too high, while it seems to perform poorly as a biomarker, showing a significant discordance between clinical and imaging assessment [50]. Conventional angiography provides clear outlines of the luminal changes of the involved arteries in detail, but it does not allow arterial wall thickening to be assessed. As it is considered an invasive method carrying significant risks, it is recommended to be used as part of vascular interventions when those are needed [5]. Equally important for the disease assessment is checking the aortic valves, ventricular function and coronary involvement using echocardiography and cardiac MRI, when needed [49].

Large vessel vasculitis can be observed in Behcet's disease, sarcoidosis, Blau syndrome, spondyloarthritis, IgG4related disease, Cogan's syndrome or relapsing polychondritis. Infections such as tuberculosis, syphilis or other bacterial infections (e.g., Staphylococcus spp.), are associated with arteritis and particularly aortitis, especially in adults. However, in most of these situations, the finding of other clinical features, pathognomonic for the specific diagnosis can differentiate among these types of large vessel arteritis, and the differential diagnosis of a patient with TA and CD should take this into account [51].

The majority of cases included in this review were treated with corticosteroids. Although corticosteroids are the mainstay of therapy and, are effective for patients with IBD and TA co-occurrence, relapse is frequent during dose tapering; thus, many patients require additional immunosuppression. Treatment of TA in children reflects treatment protocols for adults, as there is a lack of evidence in children, and at the same time there is a higher level of evidence in adult studies on TA [49]. Thus, the EULAR recommendations on adult-onset large vessel vasculitis may be used in pediatric TA patients [48]. Therefore, steroid-sparing agents, both disease-modifying antirheumatic drugs (DMARDs) and biologic DMARDs are often added to control inflammation, with anti-TNF-a monoclonal antibodies most commonly used in the cases of co-occurrence. In the majority of cases included in Table 1, the symptoms of both $\mathrm{CD}$ and TA were ameliorated by treatment with either 
infliximab or adalimumab, as 10 patients received infliximab and 3 adalimumab [15, 24, 26-28, 32, 33, 37]. On the other hand, there are some reports of patients with IBD developing TA despite infliximab treatment. As a subpopulation of patients with IBD has also subclinical TA, it is not surprising that TA would manifest while receiving treatment for IBD. The underlying mechanism, however, in patients already receiving treatment that has otherwise been proven effective in both conditions is unclear. Infliximab failure in those case may be the result of relative low doses and subsequent low serum levels. Using higher dose with shorter intervals could result in controlling patient symptoms. One other potential explanation could be that anti-TNFs itself may induce vasculitic lesions [52]. Tocilizumab is a recombinant, humanized, anti-IL-6 receptor monoclonal antibody that has shown clinical efficacy and steroid-sparing effect in TA and is currently recommended and very often used for treatment $[48,53]$; however, no supporting evidence exists for its use in $\mathrm{CD}$ and it would not be a first line option for patients with TA and CD co-occurrence.

A limitation of this study is that only a case is presented, and the rest of information are the result of retrospective analysis of literature-reported case reports and cases series; hence, the results and conclusions must be accepted with high reservations.

In summary, for patients with $\mathrm{CD}$, who develop unexplained symptoms during the course of their disease, it is important to have in mind the uncommon co-occurrence of $\mathrm{CD}$ and TA, even in adolescents. The simultaneous presentation can involve multiple organs, resulting in unique symptoms and severity of disease. TA can develop even when CD seems to be in remission. It seems that CTA or MRA are the preferred imaging diagnostic modalities to assist diagnosis. Definitely, more evidence is needed to further clarify the complex relationships and pathogenic mechanisms shared by these 2 diseases and determine an effective treatment regimen for patients who are affected by both conditions.

Author's contribution Study concept and design: FL, KA, and FS; analysis and interpretation of data: FL, KA, and PS; drafting of the manuscript: FL, KA, and SP, critically revision of the manuscript for important intellectual content: AE, PV, and FS; final approval of the version to be published: $\mathrm{LF}, \mathrm{KA}, \mathrm{PS}, \mathrm{AE}, \mathrm{PV}$, and FS.

\section{Declarations}

Conflict of interest The authors declare no relevant conflict of interest

\section{References}

1. Baumgart DC, Sandborn WJ (2012) Crohn's disease. Lancet. pp 1590-1605

2. Stone JR, Bruneval P, Angelini A et al (2015) Consensus statement on surgical pathology of the aorta from the Society for
Cardiovascular Pathology and the Association for European Cardiovascular Pathology: I Inflammatory diseases. Cardiovasc Pathol 24:267-278. https://doi.org/10.1016/j.carpath.2015.05.001

3. Kusunoki R, Ishihara S, Sato M et al (2011) Rare case of Takayasu's arteritis associated with Crohn's disease. Intern Med 50:1581-5. https://doi.org/10.2169/internalmedicine.50.5406

4. Ben Shimol J, Amital H, Lidar M et al (2020) The utility of PET/ CT in large vessel vasculitis. Sci Rep. https://doi.org/10.1038/ s41598-020-73818-2

5. Dejaco C, Ramiro S, Duftner C et al (2018) EULAR recommendations for the use of imaging in large vessel vasculitis in clinical practice. Ann Rheum Dis 77:636-643. https://doi.org/10.1136/ annrheumdis-2017-212649

6. Yan J, Hedl M, Abraham C (2017) An inflammatory bowel disease-risk variant in INAVA decreases pattern recognition receptor-induced outcomes. J Clin Invest 127:2192-2205. https://doi. org/10.1172/JCI86282

7. Gasparyan AY, Ayvazyan L, Blackmore H, Kitas GD (2011) Writing a narrative biomedical review: considerations for authors, peer reviewers, and editors. Rheumatol Int 31:1409-17. https://doi.org/ 10.1007/s00296-011-1999-3

8. Cantoro L, Di Sabatino A, Papi C et al (2017) The time course of diagnostic delay in inflammatory bowel disease over the last sixty years: an Italian multicentre study. J Crohn's Colitis 11:975-980. https://doi.org/10.1093/ecco-jcc/jjx041

9. Anwar S, Saboeiro GR, Yang A et al (2010) Large-vessel granulomatous vasculitis in Crohn's disease: a clinical pathology conference held by the division of rheumatology at hospital for special surgery. HSS J 6:206-213. https://doi.org/10.1007/ s11420-010-9177-9

10. Wakefield AJ, Sankey EA, Dhillon AP et al (1991) Granulomatous vasculitis in Crohn's disease. Gastroenterology. https://doi.org/10. 1016/0016-5085(91)70014-O

11. Ozen S, Ruperto N, Dillon MJ et al (2006) EULAR/PReS endorsed consensus criteria for the classification of childhood vasculitides. Ann Rheum Dis 65:936-941. https://doi.org/10. 1136/ard.2005.046300

12. Ozen S, Pistorio A, Iusan SM et al (2010) EULAR/PRINTO/ PRES criteria for Henoch-Schönlein purpura, childhood polyarteritis nodosa, childhood Wegener granulomatosis and childhood Takayasu arteritis: Ankara 2008. Part II: final classification criteria. Ann Rheum Dis 69:798-806. https://doi.org/10.1136/ard. 2009.116657

13. Brunner J, Feldman BM, Tyrrell PN et al (2010) Takayasu arteritis in children and adolescents. Rheumatology 49:1806-1814. https:// doi.org/10.1093/rheumatology/keq167

14. Hovde $\varnothing$, Moum BA (2012) Epidemiology and clinical course of Crohn's disease: results from observational studies. World J Gastroenterol 18:1723-1731. https://doi.org/10.3748/wjg.v18.i15. 1723

15. Sy A, Khalidi N, Dehghan N et al (2016) Vasculitis in patients with inflammatory bowel diseases: a study of 32 patients and systematic review of the literature. Semin Arthritis Rheum 45:475482. https://doi.org/10.1016/j.semarthrit.2015.07.006

16. Yassinger S, Adelman R, Cantor D et al (1976) Association of inflammatory bowel disease and large vascular lesions. Gastroenterology 71:844-6

17. Owyang C, Miller LJ, Lie JT, Fleming CR (1979) Takayasu's arteritis in Crohn's disease. Gastroenterology 76:825-8

18. Van Elburg RM, Henar EL, Bijleveld CM et al (1992) Vascular compromise prior to intestinal manifestations of Crohn's disease in a 14-year-old girl. J Pediatr Gastroenterol Nutr 14:97-100. https://doi.org/10.1097/00005176-199201000-00018

19. Hilàrio MO, Terreri MT, Prismich G et al (1998) Association of ankylosing spondylitis, Crohn's disease and Takayasu's arteritis in a child. Clin Exp Rheumatol 16:92-4 
20. Levitsky J, Harrison JR, Cohen RD (2002) Crohn's disease and Takayasu's arteritis. J Clin Gastroenterol 34:454-6. https://doi. org/10.1097/00004836-200204000-00016

21. Ohta Y, Ohya Y, Fujii K et al (2003) Inflammatory diseases associated with Takayasu's arteritis. Angiology 54:339-44. https://doi. org/10.1177/000331970305400310

22. Baqir M, Usman MHU, Adenwalla HN et al (2007) Takayasu's arteritis with skin manifestations in a patient with inflammatory bowel disease: coincidence or concurrence? Clin Rheumatol 26:996-8. https://doi.org/10.1007/s10067-006-0233-2

23. Dumarey N, Tang BNT, Goldman S et al (2007) Papillary muscle inflammation in Takayasu's arteritis revealed by FDG-PET. Eur Heart J 28:1011. https://doi.org/10.1093/eurheartj/ehl281

24. Kellermayer R, Jain AK, Ferry G et al (2008) Clinical challenges and images in GI. Gastroenterology 134(668):898. https://doi.org/ 10.1053/j.gastro.2008.01.051

25. Liu YS, Fang YH, Ruan LX et al (2009) Takayasu's arteritis associated with Crohn's disease. J Zhejiang Univ Sci B 10:631-634. https://doi.org/10.1631/jzus.B0820391

26. Katoh N, Kubota M, Shimojima Y et al (2010) Takayasu's arteritis in a patient with Crohn's disease: an unexpected association during infliximab therapy. Intern Med 49:179-82. https://doi.org/10. 2169/internalmedicine.49.2491

27. Ratuapli S, Mazlumzadeh M, Gurudu S et al (2010) Coexisting crohn's disease and takayasu's arteritis in two patients treated with anti-TNF- $\alpha$ therapies. Case Rep Gastroenterol 4:35-40. https:// doi.org/10.1159/000270919

28. Calderón R, Estrada S, Ramírez P, de la Piscina M, Salvador S Zabaleta, Enciso C, Delgado E, C FG (2010) Infliximab therapy in a patient with refractory ileocolic Crohn's disease and Takayasu arteritis. Rev Esp Enferm Dig 102:145-6

29. Taddio A, Maschio M, Martelossi S et al (2013) Crohn's disease and Takayasu's arteritis: an uncommon association. World J Gastroenterol 19:5933-5935. https://doi.org/10.3748/wjg.v19.i35. 5933

30. Caruana Galizia JP, Cassar PJ (2015) Coexistence of Takayasu arteritis and Crohn's disease in a Maltese patient. Case Rep Rheumatol 2015:1-3. https://doi.org/10.1155/2015/384257

31. Miyakawa M, Tanaka H, Yamashita M et al (2016) A case of Takayasu's arteritis detected in a patient with Crohn's disease following infliximab treatment. Nihon Shokakibyo Gakkai Zasshi 113:1761-1768. https://doi.org/10.11405/nisshoshi.113.1761

32. Talathi S, Mannion M, Colvin E et al (2018) Aortitis with an Aneurysm at initial presentation of Crohn disease. J Pediatr Gastroenterol Nutr 67:e12-e13. https://doi.org/10.1097/MPG.00000 00000001945

33. Scheicht D, Fischer F, Werthmann M-L, Strunk J (2020) Takayasu's arteritis: an unusual cause of shoulder and neck pain in a young woman with Crohn's disease. J Clin Rheumatol 26:e251e252. https://doi.org/10.1097/RHU.0000000000001103

34. Takeuchi I, Kawai T, Nambu M et al (2020) X-linked inhibitor of apoptosis protein deficiency complicated with Crohn's diseaselike enterocolitis and Takayasu arteritis: a case report. Clin Immunol 217:108495. https://doi.org/10.1016/j.clim.2020.108495

35. Kollen L, Werner O, Gavotto A (2020) Uncommon cause of chest pain in a 9-year-old boy with Crohn's disease. Gastroenterology 158:2055-2057. https://doi.org/10.1053/j.gastro.2020.02.056

36. Evirgen Şahin G, Özdel S, Özbay Hosnut F et al (2020) Takayasu's arteritis diagnosed in a patient with Crohn's disease: an unpredicted correlation. Arch Rheumatol. https://doi.org/10.46497/ archrheumatol.2021.8021

37. Polyakova I, Iannucci G, George R et al (2020) Simultaneous presentation of Crohn's disease and Takayasu arteritis in a teenage patient. J Investig Med High Impact Case Rep 8:2324709620977317. https://doi.org/10.1177/2324709620 977317
38. Pujari S, Manna S et al (2020) Pulseless diarrhea. JCR J Clin Rheumatol. https://doi.org/10.1097/rhu.0000000000001673

39. Reny JL, Paul JF, Lefèbvre C et al (2003) Association of Takayasu's arteritis and Crohn's disease: results of a study on 44 Takayasu patients and review of the literature. Ann Med Interne (Paris) 154:85-90

40. Terao C, Matsumura T, Yoshifuji H et al (2015) Brief report: Takayasu arteritis and ulcerative colitis: high rate of co-occurrence and genetic overlap. Arthritis Rheumatol 67:2226-2232. https://doi.org/10.1002/art.39157

41. Akiyama S, Fujii T, Matsuoka K et al (2017) Endoscopic features and genetic background of inflammatory bowel disease complicated with Takayasu arteritis. J Gastroenterol Hepatol 32:10111017. https://doi.org/10.1111/jgh.13640

42. Seko Y (2007) Giant cell and Takayasu arteritis. Curr Opin Rheumatol 19:39-43. https://doi.org/10.1097/BOR.0b013e3280119866

43. Pallone F, Monteleone G (2001) Mechanisms of tissue damage in inflammatory bowel disease. Curr Opin Gastroenterol 17:307312. https://doi.org/10.1097/00001574-200107000-00002

44. Soto ME, Vargas-Alarcón G, Cicero-Sabido R et al (2007) Comparison distribution of HLA-B Alleles in Mexican patients with Takayasu arteritis and tuberculosis. Hum Immunol 68:449-453. https://doi.org/10.1016/j.humimm.2007.01.004

45. Vaideeswar P, Deshpande JR (2013) Pathology of Takayasu arteritis: a brief review. Ann Pediatr Cardiol 6:52-58. https://doi.org/ 10.4103/0974-2069.107235

46. Jevon GP, Madhur R (2010) Endoscopic and histologic findings in pediatric inflammatory bowel disease. Gastroenterol Hepatol (N Y) 6:174-80

47. Mavrogeni S, Dimitroulas T, Chatziioannou SN, Kitas G (2013) The role of multimodality imaging in the evaluation of Takayasu arteritis. Semin Arthritis Rheum 42:401-412. https://doi.org/10. 1016/j.semarthrit.2012.07.005

48. Hellmich B, Agueda A, Monti S et al (2020) 2018 update of the EULAR recommendations for the management of large vessel vasculitis. Ann Rheum Dis 79:19-130. https://doi.org/10.1136/ annrheumdis-2019-215672

49. De Graeff N, Groot N, Brogan P et al (2019) European consensusbased recommendations for the diagnosis and treatment of rare paediatric vasculitides-the SHARE initiative. Rheumatol (United Kingdom) 58:656-671. https://doi.org/10.1093/rheumatology/ key322

50. Grayson PC, Alehashemi S, Bagheri AA et al (2018) 18F-fluorodeoxyglucose-positron emission tomography as an imaging biomarker in a prospective, longitudinal cohort of patients with large vessel vasculitis. Arthritis Rheumatol 70:439-449. https://doi.org/ 10.1002/art.40379

51. Berti A, Moura MC, Sechi E et al (2020) Beyond giant cell arteritis and Takayasu's arteritis: secondary large vessel vasculitis and vasculitis mimickers. Curr Rheumatol Rep. https://doi.org/ 10.1007/s11926-020-00965-w

52. Sokumbi O, Wetter DA, Makol A, Warrington KJ (2012) Vasculitis associated with tumor necrosis factor- $\alpha$ inhibitors. Mayo Clin Proc 87:739-45. https://doi.org/10.1016/j.mayocp.2012.04.011

53. Nakaoka Y, Isobe M, Tanaka $Y$ et al (2020) Long-term efficacy and safety of tocilizumab in refractory Takayasu arteritis: Final results of the randomized controlled phase 3 TAKT study. Rheumatol (United Kingdom) 59:2427-2434. https://doi.org/10.1093/ rheumatology/kez630

Publisher's Note Springer Nature remains neutral with regard to jurisdictional claims in published maps and institutional affiliations. 